\title{
Experimental Diabetic Neuropathy: Similar Changes of Slow Axonal Transport and Axonal Size in Different Animal Models
}

\author{
Rossella Medori, Herman Jenich, Lucila Autilio-Gambetti, and Pierluigi Gambetti \\ Division of Neuropathology, Institute of Pathology, Case Western Reserve University, Cleveland, Ohio 44106
}

\begin{abstract}
Analysis of slow axonal transport in sciatic and primary visual systems of BB rats with spontaneous diabetes of 2.53.5 months duration revealed a delay in transport of the neurofilament (NF) subunits, tubulin, actin, and the 60,52 , and $30 \mathrm{kDa}$ polypeptides in both systems. The polypeptides examined were not affected uniformly. Rather, the transport of the 60,52 , and $30 \mathrm{kDa}$ polypeptides and the rapidly moving component of tubulin, all constituents of the slow component b (SCb) of axonal transport, appeared to be more severely delayed than the transport of polypeptide constituents of the slow component a (SCa), such as NF and the slow-moving tubulin. Transport was not impaired in diabetic BB rats maintained normoglycemic with optimal doses of insulin. A $52 \mathrm{kDa}$ polypeptide constituent of $\mathrm{SCb}$ was identified as neuron-specific enolase, and the 30 and $60 \mathrm{kDa}$ polypeptides are likely to be aldolase and pyruvate kinase; all 3 are glycolytic enzymes. Morphometric analysis revealed that the cross-sectional area of sciatic axons was increased proximally at the level of the motor roots and decreased distally at the level of the tiblal nerve. The changes in slow transport and caliber observed in central and peripheral axonal systems of diabetic BB rats are virtually identical to those previously described in rats with streptozotocin-induced diabetes, another model of insulin-dependent diabetes. In both models, the alterations of axonal caliber are likely to be secondary to the impairment of axonal transport. The presence of the same type of impairment of axonal transport in association with the same alterations of axonal caliber in 2 different experimental models of insulin-dependent diabetes indicates that these changes are specifically associated with this type of diabetes and are also likely to occur in human diabetes. The marked transport impairment of glycolytic enzymes and/or other constituents of SCb may lead to the distal degeneration of axons that characterizes the advanced stages of diabetic neuropathy.
\end{abstract}

The axon is entirely dependent on the cell body for the supply of all its constituents, which are continuously conveyed by axonal transport (Grafstein and Forman, 1980; Lasek et al., 1984). Axonal transport, therefore, plays a basic role in maintaining

\footnotetext{
Received June 8, 1987; revised Oct. 7, 1987; accepted Oct. 8, 1987.

This work was supported by a grant from the Juvenile Diabetes Foundation International and NIH Grants NS 14509 and AG \#00795.

Correspondence should be addressed to Pierluigi Gambetti, M.D., Institute of Pathology, Case Western Reserve University, 2085 Adelbert Road, Cleveland, OH 44106

Copyright (C) 1988 Society for Neuroscience $0270-6474 / 88 / 051814-08 \$ 02.00 / 0$
}

the structural integrity of the axon, and its impairment may be the primary event in several human neuropathies, including those characterized by axonal degeneration.

Axonal degeneration is considered the hallmark of the human diabetic polyneuropathy and the main cause of functional impairment (Brown and Ashbury, 1984; Thomas and Eliasson, 1984). The pathogenetic mechanisms of diabetic neuropathy and the question of whether these mechanisms include an impairment of axonal transport remain to be defined. Three main mechanisms have been proposed: (1) alteration of endoneurial vessels, leading to widespread anoxia or multiple infarcts (see Low, 1987, for review); (2) metabolic abnormalities that include reduction of free myoinositol, $\mathrm{Na}^{+} \mathrm{K}^{+}-\mathrm{ATPase}$ activity, and rate of protein synthesis (see Low, 1987, for review); and (3) direct alteration of proteins by nonenzymatic glycosylation (Kennedy and Baynes, 1984; Panush Cohen, 1986). Each of these mechanisms could lead to axonal degeneration by impairing axonal transport or causing a direct injury to the axon. In order to define the role of axonal transport in diabetic neuropathy, the first issue that must be resolved is whether changes in axonal transport sufficiently severe to cause axonal degeneration are consistently associated with diabetes.

Previous experimental studies on axonal transport using animal models of diabetes have provided contradictory results (Bisby, 1980; Jakobsen and Sidenius, 1980; Brimijoin, 1982; Jakobsen et al., 1983). In a recent study we have shown that slow transport is similarly impaired in central and peripheral axons of rats with insulin-dependent diabetes induced by streptozoticin (SZ) (Medori et al., 1985). Individual polypeptides seemed to be affected selectively. Polypeptides transported with slow component $\mathrm{b}(\mathrm{SCb})$, which include the rapidly moving component of tubulin and several enzymes of intermediary metabolism, such as aldolase, pyruvate kinase (PK), neuron-specific enolase (NSE), and creatine phosphokinase (CPK), were delayed more than neurofilament (NF) polypeptides and the slow-moving component of tubulin, which are the main constituents of slow component a (SCa) (Lasek et al., 1984). In the same animals, the axonal caliber was increased proximally at the level of the motor roots and decreased distally at the level of the tibial nerve (Medori et al., 1985).

In this study we report that the same changes of slow transport and axonal caliber as those observed in rats with SZ-induced diabetes occur in the diabetic BB rat, a model for spontaneous insulin-dependent diabetes with many homologies to human diabetes (Rossini et al., 1985). This finding cstablishes that impairment of slow transport with alterations in axonal caliber is consistently associated with insulin-dependent diabetes in animal models and suggests that similar changes occur in human 
diabetes. Parts of this study have been presented previously (Medori et al., 1986a-c).

\section{Materials and Methods}

Animals. Age-matched diabetes-prone and diabetes-resistant male Wistar rats were obtained from the NIH-sponsored BB/Wor colony maintained at the University of Massachusetts Medical School. Diabetesprone rats had hyperglycemia and glycosuria when they were received and were given standard rat food (Purina Chow) and drinking water containing $400 \mathrm{mg} /$ liter of tetracycline ad libitum. Weight, as well as nonfasting urinary glucose and ketone levels, was measured daily. Insulin (Ultralent Zinc-Protamin) diluted $10 \mathrm{U} / \mathrm{ml}$ of sterile saline solution was administered subcutaneously to diabetic rats in amounts adjusted to maintain a permanent glycosuria with neither ketonuria nor weight loss. Occasional ketonuria was corrected by increasing the dose of insulin and by administering Ringer's lactate $(5-10 \mathrm{ml})$ hypodermically. Blood glucose levels were determined weekly in rats that had fasted for $4 \mathrm{hr}$. Two types of control animals were used: (1) diabetic-resistant rats, housed and controlled for blood glucose levels in the same manner as the diabetic rats; (2) diabetic-prone rats, initially maintained as hyperglycemic like the rats of the experimental groups and later treated with 2 daily administrations of insulin in doses adjusted to maintain normal glucose levels and suppress glycosuria and ketonuria. We refer to these 2 types of controls as nondiabetic and diabetic-normoglycemic rats, respectively.

Axonal transport. ${ }^{35} \mathrm{~S}-\mathrm{Methionine}$ was administered either by intraocular or intraspinal injection $(500 \mu \mathrm{Ci}$ in $4.5 \mu \mathrm{l}$ of sterile saline, 750 $\mu \mathrm{Ci}$ in $3 \mu \mathrm{l}$ of sterile saline, respectively) (Papasozomenos et al., 1982; Medori et al., 1985; Monaco et al., 1985). Animals were killed by intraaortic perfusion of saline, 25 and $42 \mathrm{~d}$ following the intraocular and $28 \mathrm{~d}$ following the intraspinal injection. All animals were killed at 6-10 months of age. At the time of ${ }^{35} \mathrm{~S}$-methionine administration, diabetic animals had had hyperglycemia for 2.2-3.2 months. The diabetic-normoglycemic animals were kept hyperglycemic for at least 1.5 months; then levels of glucose and ketones in urine and of glucose in blood were maintained normal for at least 1 month before ${ }^{35} \mathrm{~S}$-methionine administration. Primary visual and sciatic systems were promptly dissected out and cut into $3 \mathrm{~mm}$ segments, except for the chiasm, which measured $2 \mathrm{~mm}$. Segments were homogenized individually in electrophoresis sample buffer, total radioactivity determined in an aliquot by liquid-scintillation counting, and the remainder processed for one-dimensional PAGE (1D-PAGE) and fluorography (Bizzi et al., 1984; Medori et al., 1985; Monaco et al., 1985). The radioactivity related to the NF subunits $(200,145$, and $68 \mathrm{kDa})$, tubulin, actin, and polypeptides of $20,30,52$, and $60 \mathrm{kDa}$ was estimated by integration of the corresponding areas in scans of the 1D-PACE fluorograms obtained with a computer-assisted laser scanner (LKB Ultroscan XL) (Hoffman et al., 1983; Medori et al., 1985; Monaco et al., 1985). The percentage of the total radioactivity related to a polypeptide was expressed as a function of the distance from the eye or from the spinal cord. Transport rates of selected polypeptides were obtained by determining the location of the 50th percentile of radioactivity (Hoffman et al., 1983; Medori et al., 1985). Data were obtained from groups of 3 diabetic and 3 control rats for each experiment. A 2-tailed Student $t$ test was used for statistical analysis of the data.

Labeled polypeptides present in the proximal and distal segments of the optic system of diabetic and control rats were analyzed by 2D-PAGE and nonequilibrium $\mathrm{pH}$ gel electrophoresis (NEPHGE) (O'Farrell, 1975; O'Farrell et al., 1977; Autilio-Gambetti et al., 1982). The proteins in some of these gels were transferred to nitrocellulose (Towbin et al., 1979) and incubated with antiserum to rat neuron-specific enolase (NSE) (Polyscience, Warington, PA), and the reaction visualized by the immunoperoxidase method. The nitrocellulose membrane was then exposed to XAR film to obtain autoradiograms.

Morphometric analysis. The sciatic systems from 3 rats with 10-12 week diabetes and 3 nondiabetic controls were analyzed. Animals were fixed by intraaortic perfusion with $5 \%$ buffered glutaraldehyde, as previously described (Medori et al., 1985). The entire sciatic system was cut into $5 \mathrm{~mm}$ segments that were fixed overnight, postfixed in $2 \% \mathrm{OsO}_{4}$ and embedded in Spurr resin. Sections, $1 \mu \mathrm{m}$ thick, 10-15 and 120$125 \mathrm{~mm}$ from the spinal cord, were chosen for morphometric analysis. The size of axons was determined by a computer-assisted digitizing system, and histograms of percentage distribution of axons as a function of axonal size were obtained (Medori et al., 1985). The KolmogorovSmirnov 2-group test was used for statistical analysis of the data.

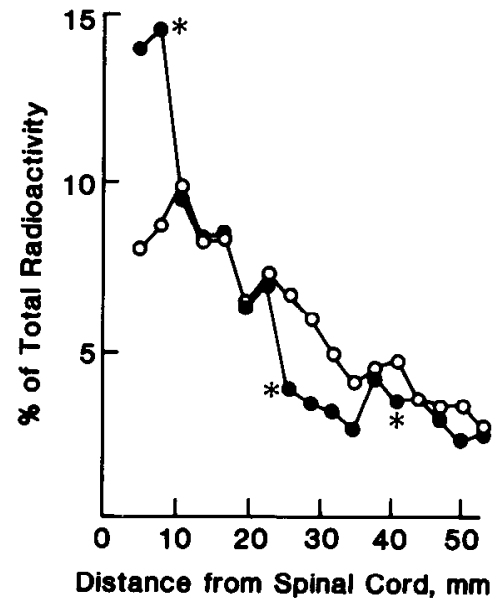

Figure 1. Distribution of the total radioactivity present in the sciatic system, $28 \mathrm{~d}$ following intraspinal injection of ${ }^{35} \mathrm{~S}$-methionine. Control animals $(\mathrm{O})$ show a peak at $12 \mathrm{~mm}$ that corresponds to $\mathrm{SCa}$, while the bulk of the radioactivity migrating with $\mathrm{SCb}$ is in segments located 23$50 \mathrm{~mm}$ from the spinal cord. In diabetic rats (C), the bulk of the radioactivity is located within the proximal $9 \mathrm{~mm}$ root segment and the radioactivity in $\mathrm{SCb}$ is markedly reduced. ${ }^{*} p<0.05$.

\section{Results}

\section{Diabetes}

In diabetic rats, blood glucose levels ranged between 600 and $950 \mathrm{mg} / \mathrm{dl}$, urinary glucose was $870-1000 \mathrm{mg} / \mathrm{dl}$, ketones were detectable not more than once a week, and the weekly increase in body weight was $0.4-2 \%$. In nondiabetic controls, blood glucose levels were $130-170 \mathrm{mg} / \mathrm{dl}$, ketonuria was not present, and body weight increased $1.4-3.4 \%$ weekly. The diabetic-normoglycemic rats had blood glucose levels ranging between 40 and $210 \mathrm{mg} / \mathrm{dl}$, only occasional glycosuria, no ketonuria, and a $1.4 \%$ weekly increase in body weight. During the diabetic phase, these animals had the same glucose and ketone levels and weight gain as the other diabetic rats.

\section{Axonal transport}

The distribution of total radioactivity along the sciatic system of diabetic rats at $28 \mathrm{~d}$ following intraspinal injection of labeled methionine is significantly different from that of controls (Fig. 1). Controls show a peak at $12 \mathrm{~mm}$, corresponding to $\mathrm{SCa}$ (Fig. 2 ), and the bulk of the radioactivity migrating with $\mathrm{SCb}$ is contained in a segment $23-50 \mathrm{~mm}$ from the spinal cord (Figs. 1, 2 ). In the diabetic rats, most of the radioactivity is located in the proximal part of the system, and the radioactivity corresponding to $\mathrm{SCb}$ is significantly reduced (Fig. 1). This distribution indicates that slow transport is delayed in the sciatic system of diabetic rats. The delay cannot be due to a reduction of the total radioactivity transported, for the total radioactivity present in the sciatic system of diabetic rats $(908 \pm 216 \times$ $10^{3} \mathrm{cpm}$ ) was not significantly different from that of controls $\left(737 \pm 251 \times 10^{3} \mathrm{cpm}\right)$.

The distribution along the sciatic system of the radioactivity present in individual bands in 1D-PAGE fluorograms shows a delay in the transport of all the polypeptides examined. The distribution of the labeled $145 \mathrm{kDa}$ NF subunit shows a distinct peak at $15 \mathrm{~mm}$ from the cord in controls, whereas in diabetic rats the major peak is at $9 \mathrm{~mm}$ (Fig. 2). Identical changes in radioactivity distribution are also seen for the other 2 NF subunits (data not shown). The changes in tubulin transport are 


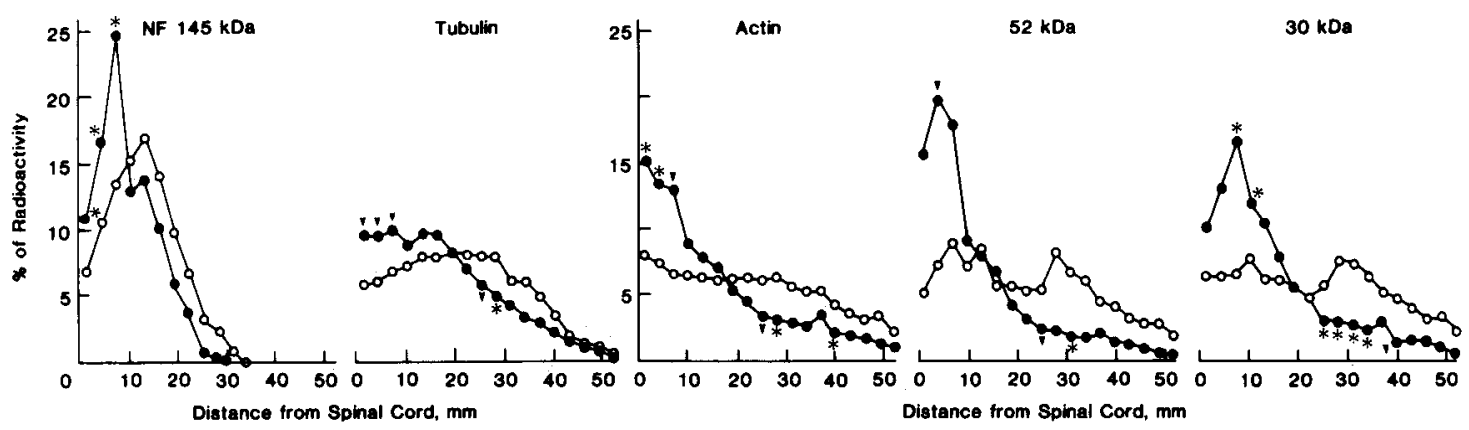

Figure 2. Distribution along the sciatic system of labeled $145 \mathrm{kDa}$ neurofilament (NF) subunit, tubulin, actin, and the 52 and $30 \mathrm{kDa}$ polypeptides. In diabetic rats (O), the peak of the radioactivity is significantly delayed for all polypeptides examined, as compared to controls $(0)$. The peak of the labeled $145 \mathrm{kDa}$ NF subunit, a representative polypeptide of $\mathrm{SCa}$, is slightly delayed. Labeled tubulin and actin, which are normally transported in both $\mathrm{SCa}$ and $\mathrm{SCb}$, as well as labeled 52 and $30 \mathrm{kDa}$ polypeptides, which are considered to be constituents of SCb, are markedly delayed in diabetic rats. Unlike in the controls, no $\mathrm{SCb}$ peak can be detected. ${ }^{*} p<0.05 ; \boldsymbol{\nabla}, p<0.01$.

more complex. In normal peripheral axons, a part of tubulin is transported with SCa and another with SCb (Fig. 2). In diabetic rats, most of the labeled tubulin is located in the proximal segments, $3-21 \mathrm{~mm}$ from the cord, and there is a reduction in radioactivity in the nerve segments where tubulin transported with $\mathrm{SCb}$ is located (Fig. 2). This distribution suggests that, in diabetic rats, all the tubulin is transported at a single rate.

A more striking difference in radioactivity distribution is seen for the major polypeptides normally migrating with $\mathrm{SCb}$ (Fig. 2). In control rats, a labeled $52 \mathrm{kDa}$ band, a major component of which is NSE (see below), and a labeled $30 \mathrm{kDa}$ polypeptide tentatively identified as aldolase (see below) both peak at about $30 \mathrm{~mm}$ from the cord. In diabetic rats, however, the peak of these labeled components coincides with that of SCa at $9 \mathrm{~mm}$ from the spinal cord. A similar distribution is also seen for the other SCb components examined, including a $60 \mathrm{kDa}$ polypeptide tentatively identified as pyruvate kinase, and a $20 \mathrm{kDa}$ polypeptide (data not shown), as well as the part of tubulin transported with $\mathrm{SCb}$. Transport rates, estimated using the 50th percentile, are decreased by $32 \%$ for the $145 \mathrm{kDa}$ NF subunit and by $50-60 \%$ for the 30 and $52 \mathrm{kDa}$ polypeptides (Table 1). Thus the transport of $\mathrm{SCb}$ polypeptides appears to be more severely impaired than that of SCa.

Very similar findings were obtained in the primary visual system. Twenty-five days following administration of ${ }^{35} \mathrm{~S}-\mathrm{me}-$ thionine, impairment of transport of NF subunits and tubulin is less severe than that of polypeptides transported with $\mathrm{SCb}$ (Fig. 3). Among the latter, actin and the 52 and $60 \mathrm{kDa}$ poly-

\begin{tabular}{|c|c|c|c|}
\hline & \multicolumn{2}{|c|}{ Transport rate $(\mathrm{mm} / 28 \mathrm{~d})^{a}$} & \multirow{2}{*}{$\begin{array}{l}\text { Rate } \\
\text { decrease (\%) }\end{array}$} \\
\hline & Control & Diabetes & \\
\hline $68 \mathrm{kDa} \mathrm{NF}$ & $13.6 \pm 1.0$ & $9.5 \pm 1.6^{*}$ & 30 \\
\hline $145 \mathrm{kDa} \mathrm{NF}$ & $13.4 \pm 1.9$ & $9.0 \pm 1.2^{*}$ & 32 \\
\hline $52 \mathrm{kDa}$ & $20.3 \pm 3.6$ & $8.9 \pm 1.7^{* *}$ & 56 \\
\hline $30 \mathrm{kDa}$ & $23.2 \pm 5.0$ & $11.7 \pm 2.8^{*}$ & 50 \\
\hline
\end{tabular}

acan location (distance from spinal cord, in $\mathrm{mm}$ ) of the 50 th percentile of labeled polypeptides in the sciatic system $25 \mathrm{~d}$ following intraspinal injection of ${ }^{35} \mathrm{~S}$ methionine. Values expressed as means \pm SD of data from 3 diabetic and 3 control rats.

${ }^{*} p<0.03 ;{ }^{* *} p<0.008$. peptides are more severely affected than the $30 \mathrm{kDa}$ polypeptide. The distribution of radioactivity at $42 \mathrm{~d}$ after labeling shows that transport of the $145 \mathrm{kDa}$ NF subunit, and, to a lesser extent, of tubulin, is slower but not blocked; the wave of these labeled polypeptides, which at $25 \mathrm{~d}$ was too proximal to be detected, has clearly moved into the system (Fig. 4). Similarly, the peak of the $30 \mathrm{kDa}$ polypeptide has moved from the middle to the end of the system. The labeled $52 \mathrm{kDa}$ polypeptides, however, are still mostly located in the proximal part of the system in diabetic rats, while in controls they have already reached the end of the system (Fig. 4). This distribution suggests that at least part of these polypeptides is transported very slowly or becomes stationary in the optic nerve. In diabetic-normoglycemic rats, all the labeled polypeptides examined appeared to be transported at a slightly faster rate than that of diabetes-resistant rats, but the differences were not statistically significant (Fig. 3).

\section{Identification of polypeptides}

The presence of labeled SCb polypeptides in the proximal region of the optic system of diabetic rats $25 \mathrm{~d}$ after labeling the retinal ganglion cells was confirmed by their location in fluorograms of 2D-PAGE and NEPHGE. In control rats, only SCa polypeptides are present in the proximal part of the optic system (Fig. $5 A$ ), while a distinct set of polypeptides transported with $\mathrm{SCb}$ is already in the distal part (Fig. $5 B$ ). In diabetic rats, labeled polypeptides of both $\mathrm{SCa}$ and $\mathrm{SCb}$ are in the proximal part of the system (Fig. $5 \mathrm{C}$ ). The mobility in the gels of the $\mathrm{SCb}$ polypeptides in the diabetic rats was indistinguishable from that of controls.

Figure 5 also clearly shows the polypeptides present in the bands analyzed in 1D-PAGE. Labeled SCb polypeptides of 20 , 30 , and $52 \mathrm{kDa}$ are well-resolved from the SCa polypeptides. There are $252 \mathrm{kDa}$ polypeptides; the more acidic one was identified as NSE on immunoblots (Fig. 6). The other $52 \mathrm{kDa}$ polypeptide is likely to be creatine kinase, which in the rat has a similar isoelectric point, but which is slightly larger in size than in guinea pig (Brady, 1982). The basic 60 and $30 \mathrm{kDa}$ polypeptides have a mobility similar to those reported for pyruvate kinase and aldolase, respectively (Brady, 1982).

\section{Morphometry}

The distribution of axons as a function of axonal cross-sectional area (Fig. 7) in diabetic rats is significantly different from that of controls $(p<0.0001 ;$ Kolmogorov-Smirnov test). In diabetic 


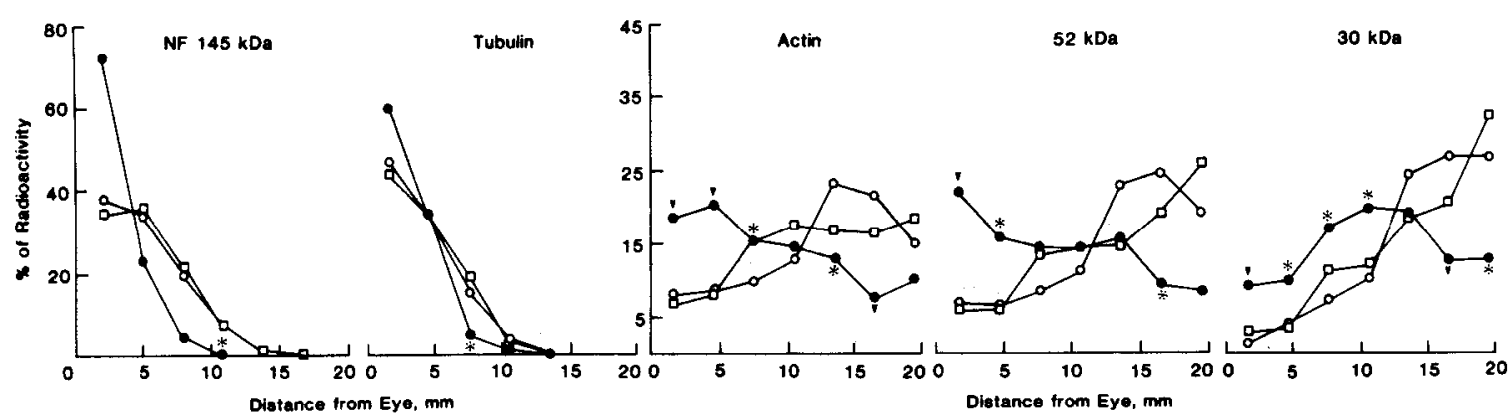

Figure 3. Distribution along the primary visual system of labeled $145 \mathrm{kDa} \mathrm{NF}$ subunit, tubulin, actin, and the 52 and $30 \mathrm{kDa}$ polypeptides in diabctic $(\odot)$, control $(O)$, and diabetic-normoglycemic ( $\square$ ) rats $25 \mathrm{~d}$ following intraocular injection of ${ }^{35}$ S-methionine. The distribution of labeled $145 \mathrm{kDa}$ NF subunit and tubulin, which in the visual system migrate exclusively with $\mathrm{SCa}$, is slightly but significantly retarded compared to control and diabetic-normoglycemic rats. More severely retarded is the transport of actin and the 52 and $30 \mathrm{kDa}$ polypeptides. While in control and diabetic-normoglycemic rats the bulk of these labeled polypeptides has reached the distal segments, in diabetic rats it is still largely located proximally. The distribution of the radioactivity in diabetic-normoglycemic rats is not significantly different from that in controls. However, transport appears to be slightly but consistently faster in diabetic-normoglycemic rats. ${ }^{*} p<0.05 ; \nabla, p<0.02$.

rats, axons are increased in size at the level of the spinal motor roots and decreased at the level of the tibial nerve. The mean cross-sectional area in proximal axons is $37.9 \pm 3.8$ in diabetic and $26.3 \pm 5.5$ in control rats $(p<0.04)$, corresponding to a $44 \%$ increase in the diabetic rats. In distal axons, the mean crosssectional area is $10.4 \pm 0.8$ in diabetic and $17.0 \pm 5.0$ in controls $(p<0.02)$, corresponding to a $31 \%$ reduction in the diabetic rats.

\section{Discussion}

Diabetic BB rats spontaneously develop an insulin-dependent diabetes caused by a cell-mediated immune destruction of the pancreatic B cells (Like et al., 1979; Nakhooda ct al., 1981a, b; Rossini et al., 1985). The onset of diabetes is abrupt, usually occurring between 2 and 4 months of age, and is characterized by hyperglycemia, ketoacidosis, polyuria, glycosuria, and ketoaciduria, which lead to death unless insulin is given (Marliss et al., 1981, 1982). Moreover, diabetic BB rats develop a progressive distal polyneuropathy with axonal degeneration in the late stages of diabetes (Mendell et al., 1981; Sima et al., 1983). Because of these and other features, diabetic BB rats are considered an excellent model of the human insulin-dependent diabetes (Nakhooda et al., 1977, 1978; Marliss et al., 1981, 1982; Mendell et al., 1981; Sima et al., 1983; Rossini et al., 1985).

The present study shows that slow axonal transport and axonal caliber are altered in this animal model of diabetes and suggests that the transport changes depend on the presence of hyperglycemia, since the changes were not observed in diabetic $\mathrm{BB}$ rats that were maintained normoglycemic with appropriate doses of insulin. Slow axonal transport is retarded in central and peripheral axons. Both $\mathrm{SCa}$ and $\mathrm{SCb}$ are affected, but $\mathrm{SCb}$ seems to be more so than SCa. The cause for the delay in transport of $\mathrm{SCa}$ and $\mathrm{SCb}$ has not been definitely established in the present study. Specifically, we did not determine whether the delay in $\mathrm{SCa}$ and $\mathrm{SCb}$ is due in part to a delay in transport initiation or solely to a decrease in transport rate, or whether a fraction of the transported proteins becomes stationary. However, in the sciatic system the delay in transport of NF proteins is likcly to be duc to the reduction of transport ratc, in view of the changes in axonal caliber that we observed (see below). In the primary visual system, the analysis of transport at 2 different points in time shows that transport impairment is not due to a block at any point along the system. At $42 \mathrm{~d}$ after labeling, some of the labeled polypeptide constituents of $\mathrm{SCb}$, such as actin and the 52 and $60 \mathrm{kDa}$ polypeptides, are still located in the proximal half of the system (Fig. 4). This finding suggests that at least a fraction of these polypeptides moves at a much slower rate or becomes stationary. The distribution of other labeled polypeptides, such as the $145 \mathrm{kDa}$ NF subunit and the $30 \mathrm{kDa}$ polypeptide, is not consistent with the presence of a stationary component, but with a reduction of transport rate. Collectively, transport and morphometric data indicate that the delay in



Figure 4. Distribution of the same labeled polypeptides shown in Figure 3 along the primary visual system of diabetic $(0)$ and control $(0)$ rats $42 \mathrm{~d}$ following administration of ${ }^{35} \mathrm{~S}$-methionine. In diabetic rats, transport of $145 \mathrm{kDa} \mathrm{NF}$ subunit and tubulin is still slightly retarded, but not blocked, as the peak of both labeled polypeptides has advanced in the optic nerve. In diabetic rats, a large fraction of labeled actin and of $52 \mathrm{kDa}$ polypeptides is still in the proximal regions of the system, suggesting that the transport of these polypeptides is markedly slowed or that a fraction of them has become stationary. Transport of the $30 \mathrm{kDa}$ polypeptides appears to be less affected. ${ }^{*} p<0.05 ; \nabla, p<0.02$. 


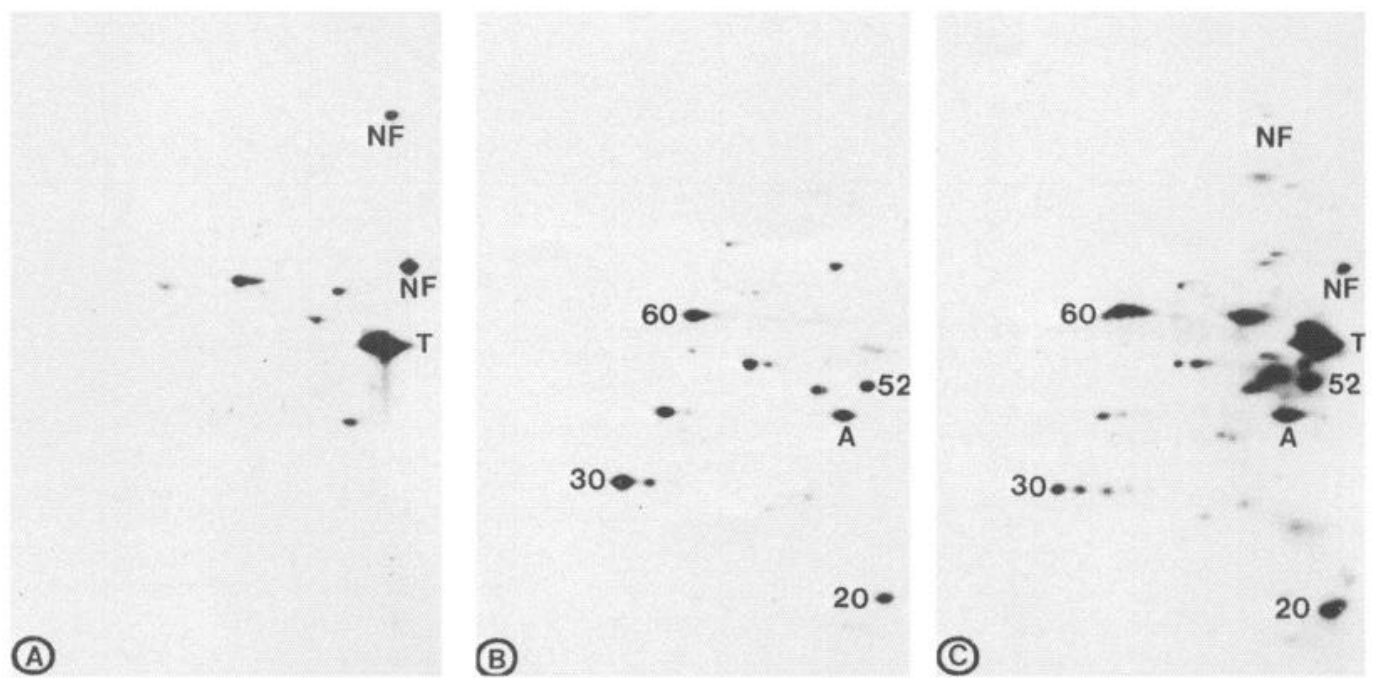

Figure 5. Fluorograms obtained from nonequilibrium $\mathrm{pH}$ gel electrophoresis (NEPHGE) of the optic system $25 \mathrm{~d}$ following intraocular administration of ${ }^{35} \mathrm{~S}$-methionine. The typical patterns of polypeptides transported with $\mathrm{SCa}$ and $\mathrm{SCb}$ are seen, respectively, in the proximal optic nerve $(A)$ and distal optic tract $(B)$ of a control rat. In contrast, the proximal optic nerve of a diabetic rat $(C)$ contains labeled polypeptides of both SCa and $\mathrm{SCb}$, confirming that transport of these polypeptides is delayed. Numbers indicate molecular weights (in $\mathrm{kDa}$ ). $T$, tubulin; $A$, actin; $N F$, neurofilament subunits.

transport of $\mathrm{SCa}$ and $\mathrm{SCb}$ is due to a reduction of transport rate and that the transport of individual polypeptides is affected differently.

In addition to the transport changes, diabetic BB rats also showed distinct alterations of axonal caliber, which increased at the level of the motor roots and decreased at the level of the tibial nerve. The axonal atrophy in the tibial nerve is similar to that previously reported by Sima et al. (1983). The earlier detection of the atrophy in our animals, after approximately 3 months of diabetes as compared to 11 months in the previous study, may be explained by the higher blood glucose levels at which animals were maintained in our study $(600-1000 \mathrm{mg} / \mathrm{dl}$ versus $300-350 \mathrm{mg} / \mathrm{dl}$ ), which may have hastened the diabetic axonopathy. In the study by Sima et al. (1983), no increase in caliber of motor root axons was detected between 6 and 11 months of diabetes. However, in that study, axon and myelin sheaths were measured together, whereas we measured axons alone, a method obviously more accurate for detecting changes of axonal caliber.

The changes in slow transport and axonal caliber of the diabetic BB rats are virtually identical to those we recently reported in rats with SZ-induced diabetes (Table 2; Medori et al., 1985). The presence of the same changes in slow transport and axonal caliber in 2 different animal models of insulin-dependent diabetes argues that these changes are specifically and consis- tently associated with this type of diabetes and therefore may also be present in human insulin-dependent diabetes.

In a morphometric study of sciatic nerve axons from rats with SZ-induced diabetes, proximal and distal changes in axonal caliber were found to correlate with changes in the number of axonal NFs and microtubules (MT) (Medori et al., 1988). It has been shown that if the number of NF and MT inserted into the axonal transport remains constant, the number of NF and MT in a given segment of the axon is inversely related to their rate of transport in that axonal segment (Wujek et al., 1986; Monaco et al., 1988). Thus, changes of axonal caliber in SZ rats are likely to be secondary to the transport alteration. The enlargement of the proximal axons can be easily attributed to the slowing of the slow transport. It is more difficult to explain the distal dwindling in the absence of transport data in these axonal regions. Preliminary experiments with axonal models indicate that distal dwindling associated with proximal enlargement occurs when the slowing of the transport is relatively less severe in the distal than in the proximal regions of the axon (R. Medori and P. Gambetti, unpublished observations). Because of the similarity of transport and caliber changes between the 2 animal models, these conclusions are likely to apply also to the BB rat. Therefore, we propose that, in the early stages of the axonopathy associated with insulin-dependent diabetes, changes in axonal caliber are a result of an alteration of slow axonal transport.
Figure 6. Identification of one of the labeled $52 \mathrm{kDa}$ polypeptides in the proximal optic nerve of a diabetic rat. Autoradiogram $(A)$ and immunoblot $(B)$ obtained from a 2D-PAGE after transfer to nitrocellulose. The labeled $52 \mathrm{kDa}$ polypeptide (NSE) in the autoradiogram is recognized by an antiserum to NSE in the immunoblot. $N F, 68 \mathrm{kDa}$; $T$, tubulin.

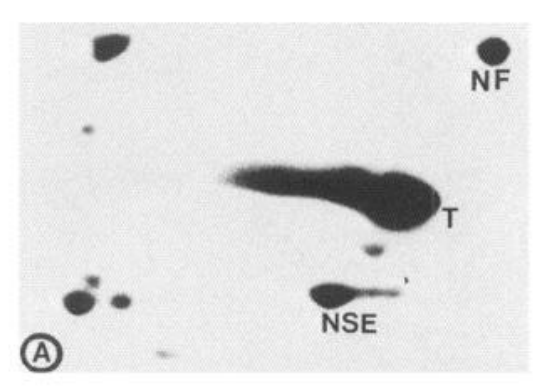

(B)






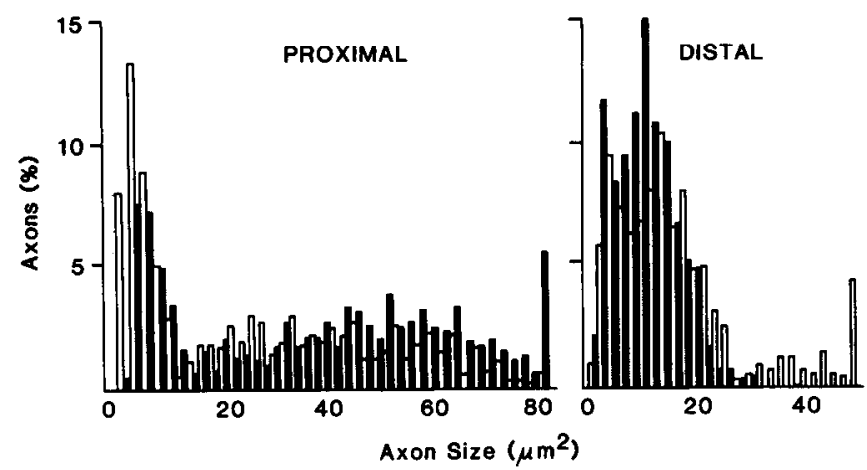

Figure 7. Histogram of percentage distribution of axons in diabetic (solid bars) and control (open bars) rats as a function of cross-sectional area. Proximal: Axons at the level of lumbar motor roots, $10-15 \mathrm{~mm}$ from the spinal cord (676 axons from control and 769 from diabetic rats). Distal: Axons at the level of the tibial nerve, $120-125 \mathrm{~mm}$ from the spinal cord (615 axons each from control and diabetic rats). Nerves from diabetic animals contain a higher number of larger axons proximally, and of smaller axons distally. Histograms from diabetic rats are significantly different from controls at both distal and proximal levels $(p<0.0001)$.

In a recent study of slow axonal transport in diabetic mutant mice, a model of non-insulin-dependent diabetes, it was concluded that transport of SCa is retarded, whereas that of SCb is unchanged (Vitadello et al., 1985). Yet the $2 \mathrm{SCb}$ polypeptides analyzed, actin, and tubulin which migrates in part with $\mathrm{SCb}$, were found to be transported at a slower rate. Thus, both SCa and $\mathrm{SCb}$ might also be affected in non-insulin-dependent diabetes.

The consistent presence of the same changes in slow transport and axonal size in experimental models of diabetes raises questions concerning the mechanism responsible for these changes and the possible role of these changes in the pathogenesis of the axonal degeneration that characterizes the later stages of human and animal diabetic neuropathy (Brown and Ashbury, 1984; Thomas and Eliasson, 1984).

Decreased neuronal protein synthesis, leading to a diminution of proteins transported in the axon, and multiple endoneurial infarcts, 2 pathogenic mechanisms proposed for diabetic neuropathy, cannot have caused the transport impairment that we have observed in SZ and BB rats (Chihara, 1981; Chihara et al., 1982; Dyck et al., 1986a, b; Johnson et al., 1986). Unlike previous investigators, we did not find that the total radioactivity of proteins transported in the sciatic system in these 2 animal models was significantly different from that of controls (Chihara, 1981; Chihara et al., 1982; Medori et al., 1985). Moreover, we analyzed distribution and not amount of transported radioactivity. Although microinfarcts have occasionally been reported in the motor roots of $\mathrm{BB}$ rats after 11 months of diabetes (Sima and Thibert, 1982), neither infarcts nor axonal dcgeneration has been observed by ourselves and others (Nakhooda et al., 1978; Mendell et al., 1981; Sima et al., 1983) in $\mathrm{SZ}$ and $\mathrm{BB}$ rats at earlier stages of diabetes. Moreover, axonal degeneration due to infarct, presumably followed by regeneration, would lead to changes of slow transport quite different from those that we have observed (Hoffman et al., 1985).

Endoneurial hypoxia, or a decreased activity of $\mathrm{Na}^{+}, \mathrm{K}^{+}-$ ATPase, might alter axonal transport by impairing basic mechanisms of energy supply. However, under these conditions, one would expect that transport of polypeptides that migrate with
Table 2. Changes in axonal transport and axonal caliber in the sciatic system of BB diabetic rats and rats with streptozotocin (SZ)induced diabetes ${ }^{a}$

\begin{tabular}{lcc} 
& BB $(\%)$ & SZ $(\%)$ \\
\hline Decrease in transport rate $^{b}$ & & \\
$68 \mathrm{kDa}$ & 30 & 22 \\
$\mathrm{NSE}$ & 56 & 40 \\
$30 \mathrm{kDa}$ & 50 & 37 \\
Changes in axonal cross-sectional area & \\
Motor roots & \\
Tibial nerve $^{d}$ & +44 & +39 \\
& -31 & -37
\end{tabular}

${ }^{a}$ Data obtained from Medori et al. (1985).

${ }^{b}$ Determined from the location of the 50th percentile (Hoffman et al., 1983).

- Distance from the spinal cord, $10-15 \mathrm{~mm}$.

${ }^{d}$ Distance from the spinal cord, $120-125 \mathrm{~mm}$.

the same transport component and presumably share the same transport mechanisms is affected to the same degree, whereas our findings are more consistent with a selective transport impairment of individual polypeptides. Moreover, it has recently been shown that anoxia similar to that supposedly present in peripheral nerve during diabetes has no effect in slow axonal transport (Nagata et al., 1987). A selective transport impairment is best explained by nonenzymatic glycosylation, a common complication of diabetes that results from the direct chemical reaction between glucose and amino groups of proteins (Kennedy and Baynes, 1984; Panush Cohen, 1986). A variety of proteins, including tubulin, have been reported to be glycosylated in experimental and human diabetes (Kennedy and Baynes, 1984; Panush Cohen, 1986). One may postulate that glycosylation interferes with the transport of individual proteins to a degree directly related to the extent of glycosylation. Williams et al. (1982) have reported that an increased amount of covalently bound reducing sugars is present in tubulin isolated from the brains of rats with SZ-induced diabetes and in high-molecular-weight material that did not enter the gel. Although individual proteins were not purified and reduced sugars were not searched in our study, we did not detect any change of molecular weight or isoelectric point, nor an increase in high-molecularweight material not entering the gels. Further studies are obviously needed to assess whether nonenzymatic glycosylation plays a role in the impairment of the slow axonal transport associated with diabetes.

Since it is likely that the transport changes of SZ and BB rats also occur in human diabetic neuropathy, it is important to know whether these changes could be responsible for the axonal degeneration that characterizes the more advanced stages of this neuropathy. The axon receives almost all of its constituents (Grafstein and Forman, 1980; Lasek et al., 1984) from the cell body through axonal transport, and it is obvious that an interruption of the transport results in axonal degeneration. However, the role that the individual components of the transport play in maintaining the structural integrity of the axon is not clear (Thomas and Eliasson, 1984). Experimental studies indicate that a severe impairment of NF transport, a major constituent of SCa, leads to alterations of axonal caliber but not to degeneration of the axon (Bizzi et al., 1984; Hoffman et al., 1985; Medori et al., 1985; Monaco et al., 1985; Gambetti et al., 1986; Wujek at al., 1986). Unlike SCa, which comprises only cytoskeletal proteins, $\mathrm{SCb}$ carries a large number of enzymes 
(Lasek et al., 1984). NSE, PK, CPK, and aldolase, all enzymes involved in the generation of energy from glycolysis, as well as calmodulin, a protein implicated in the regulation of a wide variety of enzyme activities and cell processes, have been shown to be transported with SCb (Cheung, 1980; Brady and Lasek, 1981; Brady et al., 1981). Among the SCb polypeptides whose transport is severely affected we have identified NSE. Although the identity of the other polypeptides was not determined, polypeptides of 60 and $30 \mathrm{kDa}$ with similar isoelectric points, migrating with $\mathrm{SCb}$ in the guinea pig optic system, have been identified as PK and aldolase (Brady, 1982). Thus, energy supply from the glycolytic pathway, which is required to maintain function, is likely to be impaired in the diabetic axon (Sabri and Ochs, 1972). Other metabolic pathways depending on SCb polypeptides may also be altered. Another constituent of the $\mathrm{SCb}$ complex in peripheral nerve that is affected in experimental diabetes is tubulin. Although there are differences between the tubulin transported with SCa and that with SCb (Sabri and Ochs, 1972; Brady, 1982; Morris and Lasek, 1982; Brady et al., 1984; Tashiro et al., 1984; Brady and Black, 1986; Sahenk and Brady, 1987) both are largely in polymerized form; most of SCa MT are thought to be cold and $\mathrm{Ca}^{2+}$-stable, whereas $\mathrm{SCb} \mathrm{MT}$ are in dynamic equilibrium with tubulin (Brady et al., 1984; Brady and Black, 1986; Sahenk and Brady, 1987). A sustained impairment of tubulin transport may result in a marked diminution in the number of MTs in the distal axon, which may in turn alter fast anterograde and retrograde axonal transport (Snapp et al., 1986). Thus the transport changes that we have observed in experimental insulin-dependent diabetes could lead to axonal degeneration. Future studies should determine whether axonal degeneration of human diabetic neuropathy is indeed due to impairment of the slow transport.

\section{References}

Autilio-Gambetti, L., J. Sipple, O. Sudilovsky, and P. Gambetti (1982) Intermediate filaments of Schwann cells. J. Neurochem. 38: 774-780.

Bisby, M. A. (1980) Axonal transport of labeled protein and regeneration rate in nerves of streptozotocin diabetic rats. Exp. Neurol. 69: 74-84.

Bizzi, A., R. C. Crane, L. Autilio-Gambetti, and P. Gambetti (1984) Aluminum effect on slow axonal transport: A novel impairment of neurofilament transport. J. Neurosci. 4: 722-731.

Brady, S. T. (1982) Axonal transport of glycolytic enzymes: Aldolase and pyruvate kinase (abstract). Thirteenth Annual Meeting of the American Society of Neurochemistry, Grossinger, New York.

Brady, S. T., and M. M. Black (1986) Axonal transport of microtubule proteins: Cytotypic variation of tubulin and MAPs in neurons. Ann. NY Acad. Sci. 466: 199-217.

Brady, S. T., and R. Lasek (1981) Nerve-specific enolase and creatine phosphokinase in axonal transport: Soluble proteins and the axoplasmic matrix. Cell 23: 515-523.

Brady, S. T., M. Tytell, K. Heriot, and R. J. Lasek (1981) Axonal transport of calmodulin: A physiologic approach to identification of long-term associations between proteins. J. Cell Biol. 89: 607-614.

Brady, S. T., M. Tytell, and R. J. Lasek (1984) Axonal tubulin and axonal microtubules: Biochemical evidence for cold stability. J. Cell Biol. 99: 1716-1724.

Brimijoin, W. S. (1982) Abnormalities of axonal transport: Are they a cause of peripheral nerve disease? Mayo Clin. Proc. 57: 707-714.

Brown, M. J., and A. K. Ashbury (1984) Diabetic neuropathy. Ann. Neurol. 15: 2-12.

Cheung, W. Y. (1980) Calmodulin plays a pivotal role in cellular regulation. Science 207: 19-27.

Chihara, E. (1981) Impairment of protein synthesis in the retinal tissue in diabetic rabbits: Secondary reduction of fast axonal transport. $\mathbf{J}$. Neurochem. 37: 247-250.

Chihara, E., M. Sakugawa, and S. Entani (1982) Reduced protein synthesis in diabetic retina and secondary reduction of slow axonal transport. Brain Res. 250: 363-366.

Dyck, P. J., J. L. Karnes, and P. O'Brien (1986a) The spatial distribution of fiber loss in diabetic polyneuropathy suggests ischemia. Ann Neurol. 19: 440-449.

Dyck, P. J., A. Lais, J. L. Karnes, P. O'Brien, and R. Rizza (1986b) Fiber loss is primary and multifocal in sural nerves in diabetic polyneuropathy. Ann. Neurol. 19: 425-439.

Gambetti, P., S. Monaco, L. Autilio-Gambetti, and L. M. Sayre (1986) Chemical neurotoxins accelerating axonal transport of neurofilaments. In Cytoskeleton: A Target for Toxic Agents, T. W. Clarkson, P. R. Sager, and T. L. M. Syversen, eds., pp. 129-142, Plenum, New York,

Grafstein, B., and D. S. Forman (1980) Intracellular transport in neurons. Physiol. Rev. 60: 1167-1283.

Hoffman, P. N., R. J. Lasek, J. W. Griffin, and D. L. Price (1983) Slowing of the axonal transport of neurofilament proteins during development. J. Neurosci. 3: 1694-1700.

Hoffman, P. N., G. W. Thompson, J. W. Griffin, and D. L. Price (1985) Changes in NF transport coincide temporally with alterations in the caliber of axons in regenerating motor fibers. J. Cell Biol. 101:13321340.

Jakobsen, J., and P. Sidenius (1980) Decreased axonal transport of structural proteins in steptozotocin diabetic rats. J. Clin. Invest. 66 : 292-297.

Jakobsen, J., W. S. Brimijoin, and P. Sidenius (1983) Axonal transport in neuropathy. Muscle Nerve $6: 164-166$.

Johnson, P. C., S. C. Doll, and D. W. Cromey (1986) Pathogenesis of diabetic neuropathy. Ann. Neurol. 19: 450-457.

Kennedy, L., and J. W. Baynes (1984) Non-enzymatic glycosylation and the chronic complications of diabetes: An overview. Diabetologia 26: 93-98.

Lasek, R. J., J. A. Garner, and S. I. Brady (1984) Axonal transport of the cytoplasmic matrix. J. Cell Biol. 99: 212-221.

Like, A. A., A. A. Rossini, D. L. Guberski, M. C. Appel, and R. M. Williams (1979) Spontaneous diabetes mellitus. Reversal and prevention in the $\mathrm{BB} / \mathrm{W}$ rat with antiserum to rat lymphocytes. Science 206: 2421-2423.

Low, P. A. (1987) Recent advances in the pathogenesis of diabetic neuropathy. Muscle Nerve 10:121-128.

Marliss, E. B., A. A. F. Sima, and A. F. Nakhooda (1981) Spontaneous diabetes in the "BB" Wistar rat. In Etiology and Pathogenesis of Insulin-Dependent Diabetes Mellitus, J. M. Martin, R. M. Ehrlich, and F. J. Holland, eds., pp. 251-274, Raven, New York.

Marliss, E. B., A. F. Nakhooda, P. Poussier, and A. A. F. Sima (1982) The diabetic syndrome of the "BB" Wistar rat. Possible relevance of type 1 (insulin-dependent) diabetes in man. Diabetologia 22: 225232.

Medori, R., L. Autilio-Gambetti, S. Monaco, and P. Gambetti (1985) Experimental diabetic neuropathy: Impairment of slow transport with changes in axon cross-sectional area. Proc. Natl. Acad. Sci. USA 82. 7716-7720.

Medori, R., H. Jenich, L. Autilio-Gambetti, and P. Gambetti (1986a) Role of axonal transport in the pathogenesis of diabetic polyneuropathy (abstract). Tenth International Congress of Neuropathology, p. 317 , Stockholm.

Medori, R., H. Jenich, O. Avila, L. Autilio-Gambetti, and P. Gambetti (1986b) Distinctive effects of diabetes on slow axonal transport (abstract). J. Neuropathol. Exp. Neurol. 45: 351.

Medori, R., H. Jenich, O. Avila, L. Autilio-Gambetti, and P. Gambetti (1986c) Distinctive effects of diabetes on slow axonal transport (abstract). Muscle Nerve 9: 115.

Medori, R., L. Autilio-Gambetti, H. Jenich, and P. Gambetti (1988) Changes in axon size and slow axonal transport are related in experimental diabetic neuropathy. Neurology (in press).

Mendell, J. R., Z. Sahenk, J. R. Warmolts, J. K. Marshall, and P. Thibert (1981) The spontaneously diabetic BB Wistar rat. Morphologic and physiologic studies of peripheral nerve. J. Neurol. Sci. 52: 103-115.

Monaco, S., L. Autilio-Gambetti, D. Zabel, and P. Gambetti (1985) Giant axonal neuropathy: Acceleration of neurofilament transport in optic axons. Proc. Natl. Acad. Sci. USA 82: 920-924.

Monaco, S., L. Autilio-Gambetti, R. J. Lasek, M. J. Katz, and P. Gambetti (1988) Drug-increased neurofilament transport rate: Decreases in neurofilament number and in axon diameter. J. Neuropathol. Exp. Neurol. (in press). 
Morris, J. R., and R. J. Lasek (1982) Stable polymers of the axonal cytoskeleton: The axoplasmic ghost. J. Cell Biol. 32: 152-158.

Nagata, H., W. S. Brimijoin, P. Low, and J. D. Schmelzer (1987) Slow axonal transport in experimental hypoxia and in neuropathy induced by $p$-bromophenylacetylurea. Brain Res. 422: 319-326.

Nakhooda, A. F., A. A. Like, C. I. Chappel, F. I. Murray, and E. B. Marliss (1977) The spontaneously diabetic Wistar rat. Metabolic and morphologic studies. Diabetes 26: 100-122.

Nakhooda, A. F., A. A. Like, C. I. Chappel, C. N. Wei, and E. B. Marliss (1978) The spontaneously diabetic Wistar rat: Studics prior to and during development of the overt syndrome. Diabetologia 14: 199207.

Nakhooda, A. F., A. A. F. Sima, P. Poussier, and E. B. Marliss (1981a) Passive transfer of insulitis from the BB-Wistar rat to nude mouse. Endocrinology 109: 2264-2265.

Nakhooda, A. F., A. A. F. Sima, P. Poussier, and E. B. Marliss (1981b) Immunity in the spontaneously diabetic BB-Wistar rat. Passive transfer of insulitis in the presence of donor rat lymphopenia. Clin. Exp. Med. 4: 35B.

O'Farrell, P. H. (1975) High resolution two dimensional electrophoresis of proteins. J. Biol. Chem. 250: 4007-4021.

O'Farrell, P. Z., H. M. Goodman, and P. H. O'Farrell (1977) High resolution two-dimensional electrophoresis of basic as well as acidic proteins. Cell 12:1133-1142.

Panush Cohen, M. (1986) Diabetes and Protein Glycosylation: Measurement and Biologic Relevance. Springer-Verlag, New York.

Papasozomenos, S. C., M. Yoon, R. Crane, L. Autilio-Gambetti, and P. Gambetti (1982) Redistribution of proteins of fast axonal transport following administration of $\beta, \beta^{\prime}$-iminodipropionitrile: $\mathrm{A}$ quantitative study. J. Cell Biol. 95: 672-675.

Rossini, A. A., J. P. Mordes, and A. A. Like (1985) Immunology of insulin-dependent diabetes mellitus. Annu. Rev. Immunol. 3: 289320.

Sabri, M. I., and S. Ochs (1972) Relation of ATP and creatine phos- phate to fast axoplasmic transport in mammalian nerve. J. Neurochem. 19: 2821-2828.

Sahenk, Z., and S. T. Brady (1987) Axonal tubulin and microtubules: Morphologic evidence for stable regions on axonal microtubules. Cell Motil. Cytoskel. 8: 155-164.

Sima, A. A. F., and P. Thibert (1982) Proximal motor neuropathy in the BB-Wistar rat. Diabetes 31: 784-788.

Sima, A. F., M. Bouchier, and H. Christensen (1983) Axonal atrophy in sensory nerves of the diabetic BB-Wistar rat. A possible early corrclatc of human diabetic neuropathy. Ann. Neurol. 13: 264-272.

Snapp, B. J., R. D. Vale, M. P. Sheetz, and T. S. Reese (1986) Microtubules and the mechanism of directed organelle movement. Ann. NY Acad. Sci. 466: 909-918.

Tashiro, L. T., M. Kurokawa, and Y. Komiya (1984) Two populations of axonally transported tubulin differentiated by their interactions with neurofilaments. J. Neurochem. 43: 1220-1225.

Thomas, P. K., and S. G. Eliasson (1984) Diabetic neuropathy. In Peripheral Neuropathy, P. J. Dyck, P. K. Thomas, E. H. Lambert, and R. Bunge, eds., pp. 1773-1810, Saunders, Philadelphia, PA.

Towbin, H., T. Staehelin, and J. Gordon (1979) Electrophoretic transfer of proteins from polyacrylamide gels to mitrocellulose sheets: Procedure and some applications. Proc. Natl. Acad. Sci. USA 76: 4350-4354.

Vitadello, M., G. Filliatreau, J. L. Dupont, R. Hassig, A. Gorio, and L. Di Giamberardino (1985) Altered axonal transport of cytoskeletal proteins in the mutant diabetic mouse. J. Neurochem. 45: 860-868.

Williams, S. K., N. L. Howarth, J. J. Devenny, and M. W. Bitensky (1982) Structural and functional consequences of increased tubulin glycosylation in diabetes mellitus. Proc. Natl. Acad. Sci. USA 79: 6546-6550.

Wujek, J. R., R. J. Lasek, and P. Gambetti (1986) The amount of slow axonal transport is proportional to the radial dimensions of the axon. J. Neurocytol. 15: 75-83. 